\title{
Quantitative Trait Loci Affecting Calving Traits in Danish Holstein Cattle
}

\author{
J. R. Thomasen, ${ }^{*} \dagger^{1}$ B. Guldbrandtsen, ${ }^{*}$ P. Sørensen, ${ }^{*}$ B. Thomsen, ${ }^{*}$ and M. S. Lund ${ }^{*}$ \\ *University of Aarhus, Faculty of Agricultural Sciences, Department of Genetics and Biotechnology, Research Center Foulum, \\ DK-8830 Tjele, Box 50, Denmark \\ †Viking Genetics, Ebeltoftvej 16, Assentoft, DK-8900 Randers, Denmark
}

\section{ABSTRACT}

The objectives of this study were 1) to detect quantitative trait loci (QTL) affecting direct and maternal calving traits at first calving in the Danish Holstein population, 2) to distinguish between pleiotropic and linked QTL for chromosome regions affecting more than one trait, and 3) to detect QTL affecting stillbirth and calving difficulties but not calf size that could be used in selection to improve calving performance. Progenytested sons $(2,297)$ were genotyped for 356 microsatellites in 34 grandsire families on all 29 autosomes. A total of 27 significant QTL on 17 chromosomes were detected using a between-families linear regression model. For the direct calving traits, 4 QTL significantly affected calving difficulty, 5 QTL affected stillbirth, and 7 QTL affected calf size subjectively assessed by the farmer as a categorical trait. When the maternal components of the same traits were tested, there were significant effects of 3 QTL on calving difficulty, 6 QTL on stillbirth, and 2 QTL on calf size. The variance component mapping approach was used to estimate the relative posterior probability of linkage and pleiotropic models. The most probable model indicated a pleiotropic QTL on chromosome 12 and 25 and a linked QTL on chromosome 7 and 26. Chromosome 18 seemed to harbor a QTL with a pleiotropic effect on the direct calving traits and linked to maternal stillbirth. Markers on chromosomes $3,4,7,10,12,18,21,24,26$, and 28 can be used to select new breeding candidates to produce daughters with more efficient calving performance.

Key words: quantitative trait locus, calving difficulty, stillbirth, Bos taurus

\section{INTRODUCTION}

Stillbirth (SB), calving difficulty (CD), and the size of calf at birth (CS) are economically important calving

Received August 10, 2007.

Accepted January 7, 2008.

${ }^{1}$ Corresponding author: Jorn.RThomasen@agrsci.dk traits included in the Danish dairy cattle breeding program (Pedersen, 2003). The incidence of SB for Holstein cattle has increased in several Holstein populations during the last 2 decades (Hansen, 2004). The increased incidence of SB reduces the potential number of replacement heifers in dairy cattle herds and is an ethical and economic concern.

Calving performance is influenced by the genotypes of both the dam and the calf itself. Hence, both direct (calf) and maternal (dam) genetic components are included in the model for the calving traits. The direct effect refers to the additive genetic effect of the genotype of the calf and the maternal effect to the additive genetic effect of the genotype of the calf's dam.

In Danish Holsteins the heritability $\left(\mathbf{h}^{2}\right)$ estimates of calving traits (Hansen et al., 2004) measured as a direct sire effect $\left(h^{2}=0.05\right.$ to 0.19$)$ are higher than the heritability estimates of the calving traits measured as a maternal grandsire effect $\left(\mathrm{h}^{2}=0.04\right.$ to 0.06$)$. The genetic correlation among calving traits measured as a direct sire effect ( 0.69 to 0.93 ) are markedly higher than the genetic correlation among calving traits measured as a maternal grandsire effect (0.01 to 0.62).

Several QTL have been detected for calving traits in other Holstein populations (Elo et al., 1999; Schrooten et al., 2000; Kühn et al., 2003). These QTL have been detected using single QTL and single-trait models. However, the strong genetic correlations between the calving traits indicate that some QTL may affect more than one trait. Some QTL are located at the same chromosomal position for different traits. If the QTL affects multiple traits, it is important to investigate whether it is a pleiotropic or linked QTL that affects the traits. This knowledge can be used to obtain more efficient selection progress against SB and CD.

Calving difficulty and SB occur most frequently at first calving and the heritabilities are higher at first calving (Hansen, 2004). Genetic correlations for direct calving traits between first and later calvings were estimated to range from 0.97 to 0.99 and from 0.81 to 0.89 for maternal calving traits (Aamand, 2002). For these 
reasons this study only focused on calving traits at first calving.

Because of the economic and ethical importance of the calving traits, both direct and maternal effects are already included in the breeding goal with significant economic weights. However, inclusion of genetic markers for calving traits could make the selection for calving performances even more efficient.

The aims of this study were 1) to detect QTL affecting direct and maternal SB, CD, and CS at first calving in the Danish Holstein population, 2) to distinguish between pleiotropic and linked QTL for chromosomes affecting more than one trait, and 3) to detect QTL affecting SB and CD without affecting CS that could be used in selection programs to improve calving performance.

\section{MATERIALS AND METHODS}

\section{Animals}

A total genome scan was carried out in the Danish Holstein population. Marker and phenotypic data were collected according to a granddaughter design (Weller et al., 1990). Numbers of grandsire families vary between chromosomes because the original design comprised 19 grandsire families. Subsequently, additional families were typed for chromosomes deemed interesting for QTL mapping based on results from families already typed. Chromosomes 2, 4, 5, 6, 9, 12, 13, 19, $20,22,23,24$, and 25 were analyzed in 19 grandsire families and 1,592 sons; chromosome 17 in 20 grandsire families and 1,630 sons; chromosome 14 in 24 grandsire families and 1,848 sons; chromosome 28 in 33 grandsire families and chromosomes 1, 3, 7, 8, 10, 11, $15,16,18,21,26,27$, and 29 were analyzed in 34 grandsire families and 2,297 sons. Numbers of sons per sire ranged from 20 to 106, with an average family size of 84 for the 19 families and 68 for the 34 families. Sires and their sons were genotyped for marker information whereas phenotypic records were taken from granddaughter performances.

\section{Markers and Maps}

Markers and their positions were chosen from the Web site of the Meat Animal Research Center (http:// www.marc.usda.gov/genome/genome.html; USDAMARC, Clay Center, NE). All 29 autosomes were covered using 356 microsatellite markers with an average marker spacing of $8.60 \mathrm{cM}$; markers and positions are given in Table 1. Genotypes were determined on an automated sequence analyzer. Inconsistent marker types and markers exhibiting evidence of segregation distortion were discarded.
Numbers of informative markers per chromosome were used as a criterion for the information level on each chromosome. Numbers of informative markers were calculated as the average number of heterozygous markers in the typed grandsires on each chromosome.

\section{Phenotypic Data}

Calving traits were each assessed as subjective scores on the farm by the farmers. Only first-parity calvings were included. Stillbirth was scored as an all-or-none trait; and the calf was considered stillborn if it died within the first $24 \mathrm{~h}$. Calving difficulty and CS were scored as categorical traits on a scale from 1 to 5 . A score of 1 was assigned for easy calving without assistance and 5 for the very difficult calving with veterinarian assistance. A score of 1 was assigned for small calves and 5 for the biggest calves born in the herd. For further details, see Danish Cattle Federation (2006).

The data used were EBV for traits of sons calculated using a BLUP single-trait sire model, ignoring family structure among sires and correlation among the traits. Fixed effects in the models were class effects of herd $x$ year interaction, year $\times$ season interaction, age of cow $\times$ region interaction, and sex of calf $\times$ year interaction. The random effects were sire of calf, sire of cow (maternal grandsire of calf), and residuals. The calving traits considered were SB, CD, and CS after first calving. The breeding values were estimated both as a "direct" effect (D) of the sire in the calf and as a "maternal" effect (M) of the sire in the mother of the calf, giving a total of 6 traits for the QTL analysis. Permanent environmental effects could in this study be ignored, because we only considered QTL for calving ability at first calving.

For direct effects the model used was

$$
y_{i j k}=x_{i j k} \beta+c s_{i j k} s[d(i j k)]+s(i j k)+e_{i j k}
$$

where $y_{i j}$ is the phenotypic value for the $k$ th first-parity offspring of the $j$ th son of grandsire $i, x_{i j k}$ is a design vector pertaining to calf $i j k, \beta$ is the vector of fixed effects, $c s_{i j k}$ is the size of calf $i j k, s[d(i j k)]$ is the maternal grand sire of offspring $i j k, s(i j k)$ is the sire of calf $i j k$, and $e_{i j k}$ is a random residual for calf $i j k$. All random effects have expectation 0.

For maternal effects the model used was

$$
y_{i j k}=x_{i j k} \beta+c s_{i j k} s[d(i j k)]+s(i j k)+e_{i j k},
$$

where $y_{i j k}$ is the phenotypic value for the $k$ th first-parity offspring of a daughter of the $j$ th son of grandsire $i, x_{i j k}$ is a design vector pertaining to calf of daughter $i j k, \beta$ is the vector of fixed effects, $c s_{i j k}$ is the size of calf of daughter $i j k, s[d(i j k)]$ is the maternal grand sire of 
Table 1. Distribution of the markers across the chromosomes

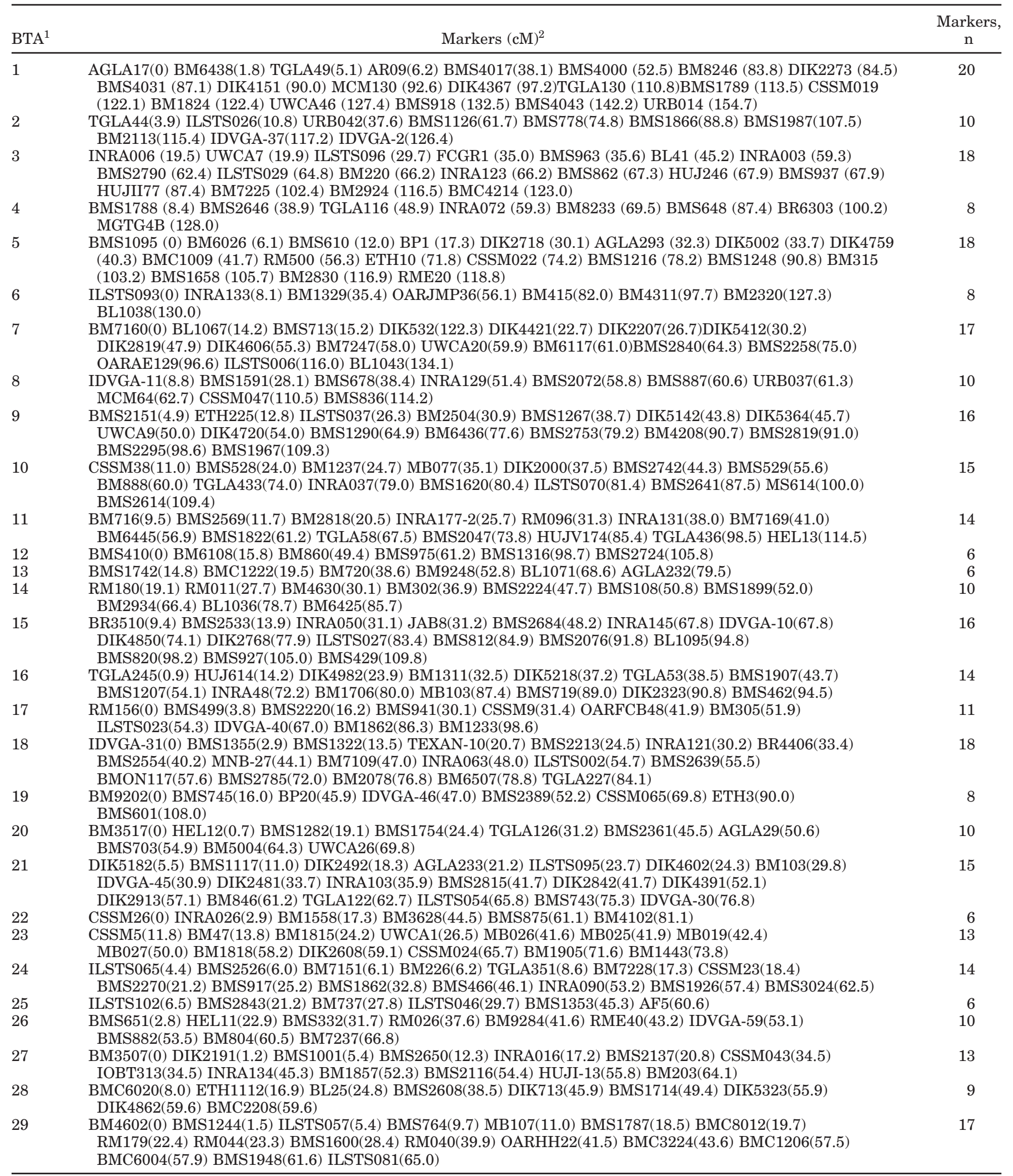

\footnotetext{
${ }^{1} \mathrm{BTA}=$ Bos taurus autosome.

${ }^{2}$ Markers are chosen from www.marc.usda.gov/genome/genome.html; positions of the markers are from 2006.
} 
daughter $i j k, s(i j k)$, is the sire of daughter $i j k$, and $e_{i j k}$ is a random residual for the calf of daughter ijk. All random effects have expectation 0 .

\section{QTL Analysis}

A series of analyses were performed. First, the data were analyzed with a single QTL regression approach using all markers on the chromosome simultaneously for both between- and within-family analyses. If between-family chromosome-wise significance was obtained at a $5 \%$ threshold level for at least 2 calving traits, then multitrait models were fitted using a variance component method. The fitted models were designed to distinguish if the identified QTL was most likely 1 QTL affecting both traits (pleiotropy) or 2 linked QTL, each affecting 1 trait. For details of the models see Lund et al. (2003). All models were fitted using AIREML (Johnson and Thompson, 1994; Madsen et al., 1994) as implemented in the DMU package (Madsen et al., 2006).

Regression Analysis. Marker linkage phase in the sires was determined based on offspring marker types and subsequently were assumed to be known without error. Segregation probabilities at each map position were calculated using information from all markers on the chromosome simultaneously using Haldane's mapping function (Haldane, 1919). When it was not possible to distinguish unambiguously whether an allele was inherited from the sire or the dam, the allele frequencies were used to calculate the segregation probabilities. Population allele frequencies of the markers were estimated from the sons maternally inherited chromosomes and grandsire chromosomes using an expectation-maximization (EM) algorithm (Dempster et al., 1977). Allele frequencies were subsequently assumed known without error. Phenotypes were regressed onto the segregation probabilities. Significance thresholds were calculated using permutation tests performing 1,000 permutations (Churchill and Doerge, 1994).

Genome-wise false discovery rates were calculated for each trait separately in $R$ version 2.5.1 (http:// www.r-project.org/) using the library $q$-value version 1.1 in the $q$-value package implementing the method by Storey and Tibshirani (2003). The $q$-values were calculated for each trait separately.

Multitrait Analysis. For chromosomes affecting 2 or more traits, multitrait analyses were performed to test whether the data were better described by a single QTL affecting both traits or by 2 linked QTL, each affecting 1 trait. Description of these models can be found in Buitenhuis et al. (2007) and Lund et al. (2003).

The pleiotropic and linked-QTL models can be written as:

$$
y=X \beta+Z u+\sum_{i=1}^{n q t l} W_{i} q_{i}+e,
$$

where $\mathbf{y}$ is an $\mathrm{n} \times \mathrm{t}$ vector of observations on $t=\{1,2\}$ traits, $\mathbf{X}$ is a matrix relating records to the fixed effects, $\boldsymbol{\beta}$ is a vector of fixed effects, $\mathbf{Z}$ is a matrix relating records to individuals, $\mathbf{u}$ is a vector of additive polygenic effects, $\mathbf{W}$ is a matrix relating each individual's record to its QTL effect, $\mathbf{q}_{\mathbf{i}}$ is a vector of additive QTL effects corresponding to the $i$ th QTL, and $\mathbf{e}$ is a vector of residuals. The number of QTL, $\mathrm{n}_{\mathrm{qt}}$, was assumed to be equal to 1 or 2 . The random variables $\mathbf{u}, \mathbf{q}$, and $\mathbf{e}$ were assumed to be multivariate normally distributed and mutually uncorrelated. Specification of pleiotropic and linked QTL models followed Lund et al. (2003), except that no linkage disequilibrium information was included in the analysis of this paper. To obtain computational efficiency and stability, an exhaustive search for linked QTL was avoided by fitting the linked QTL model at the previously estimated positions from the singletrait variance component model. The pleiotropic model was fitted at positions in the region spanning the 2 positions of the linked single-trait QTL model.

Model Selection Between Pleiotropic and Linked-QTL Models. The pleiotropic and linked-QTL models cannot be compared using likelihood ratio tests because the models are not nested. Therefore, the Bayesian information criterion (BIC) (Schwarz, 1978; Kass and Raftery, 1995) was used to evaluate which model is favored. The 2 models incorporate the same number of parameters, and consequently, the BIC simplifies to

$$
2 \log \left[\frac{p\left(y \mid \hat{\theta}_{\text {linkage }} M_{\text {linkage }}\right)}{p\left(y \mid \hat{\theta}_{\text {pleiotropy }} M_{\text {pleiotropy }}\right)}\right] .
$$

If the 2 models are assumed equally likely a priori, the result using this criterion is an approximation to the Bayesian posterior probability of the pleiotropic model relative to the posterior probability of the linked QTL model. In this study, the approximate Bayes factor,

$$
\left[\frac{p\left(y \mid \hat{\theta}_{\text {pleiotropy }} M_{\text {pleiotropy }}\right)}{p\left(y \mid \hat{\theta}_{\text {linkage }} M_{\text {linkage }}\right)}\right]
$$

was used for comparison of the pleiotropic model to the linked model. Another less formal criterion used to indicate which model is more likely is the estimated correlation between QTL effects of the 2 traits $\left(\mathrm{r}_{\mathrm{Q} 12}\right)$ from the pleiotropic model. The rationale behind using $\mathrm{r}_{\mathrm{Q} 12}$ is that if the 2 traits are under influence of a biallelic pleiotropic QTL, the true value of $\mathrm{r}_{\mathrm{Q} 12}$ will be plus or minus 1. 


\section{RESULTS}

\section{Regression Analysis}

The chromosome-wise regression test (Table 2) indicated a total of 27 significant tests $(P<0.05)$ for calving traits in first lactation on 17 different chromosomes. Fifteen of the QTL were related to the direct effects and 12 QTL were related to the maternal effects. In this study, we detected QTL for all analyzed traits, but in particular for D-CS with $7(P<0.05)$ and M-SB with 6 significant QTL.

The average number of informative markers per grandsire family varied from 3.0 to 8.5 informative markers per chromosome. Fifteen percent of the significant QTL had calculated $q$-values below 5\%.

The QTL that were significant in across family tests were also significant in within family tests at the $5 \%$ level in 0 to 7 Holstein families.

\section{Multitrait Analysis}

Seven chromosomes had more than 1 significant QTL in the same region and were further examined for the presence of pleiotropic or linked QTL. Only Bos taurus autosome (BTA) 18 had more than 2 significant QTL. Table 3 has test results from the variance components model (Sørensen et al., 2003). On BTA7, 2 significant QTL were detected for the direct effects on SB and CS with an estimated distance between the 2 QTL positions of $26 \mathrm{cM}$. For this chromosome, the Bayes factor was calculated to be 0.3 ; and the correlation between the QTL effects was low (0.35). On this chromosome, there may be 2 linked QTL. For BTA8 the analysis was inconclusive because of convergence problems with the pleiotropic model. For BTA12 there was evidence of a pleiotropic QTL, with a Bayes factor of 27 and a high correlation between the 2 QTL (0.99). On BTA18, 4 significant QTL were detected and analyzed in pair-wise multitrait analyses. The calculated Bayes factors among the group of direct-calving traits (D-SB, D-CS, D-CD) were all high $(27$ to $1,806,411)$, which strongly supports a pleiotropic model. In contrast, the Bayes factors between MSB and D-CD and D-CS were lower than 1 (0.7) but did not clearly favor the linked model. The results of the analysis strongly supported a pleiotropic QTL for the group of direct traits, whereas the relation to M-SB was inconclusive. The calculated correlations between the QTL support the conclusions from the Bayes factor analysis with higher correlations existing within the group of direct-calving traits (0.87 to 0.93 ) than for MSB with direct traits $(0.49$ to 0.71$)$. For BTA22 the pleiotropic QTL model was slightly favored (Bayes factor $=3.7$ ) compared with the 2-QTL model. However, with an $\mathrm{r}_{\mathrm{q}}=0.72$ and with an estimated distance of 14
cM between the 2 QTL positions, there was no conclusive evidence for a pleiotropic QTL. The analysis for BTA25, however, clearly favored the pleiotropic model with a high Bayes factor of 548 and strong correlation $\left(\mathrm{r}_{\mathrm{q}}=1.00\right)$ between $\mathrm{D}-\mathrm{CD}$ and D-CS. In contrast, the 2QTL model was slightly favored for BTA26 with a Bayes factor of 0.13 and a correlation close to zero. For BTA28 the 1-QTL model was favored (Bayes factor $=3.7$ ) compared with the 2-QTL model. But with $\mathrm{r}_{\mathrm{q}}=0.78$ and an estimated distance of $10 \mathrm{cM}$ between the $2 \mathrm{QTL}$ positions, there was no conclusive evidence for either a pleiotropic or linked QTL.

\section{DISCUSSION}

Several QTL affecting both direct and maternal calving traits were identified in this study. However, because of the high number of performed regression tests, it is expected that some of the detected QTL are false positives. In total, 4,674 tests were carried out. At the $5 \%$ significance level, 234 QTL across all chromosomes are expected to be false positive. The number of tests for the chromosome-wise regression test between family analysis was 6 traits $\times 29$ chromosomes $=174$. Of these, 27 were significant at a $5 \%$ level for a false discovery rate of $174 \times 0.05 / 27=0.3$, which indicates that $30 \%$ of the detected QTL are expected to be false positives.

For 9 chromosomes we detected only 1 significant QTL affecting 1 trait. The most reliable QTL in this category was found on BTA3 for D-SB. This chromosome has a dense marker map, and the QTL segregated in 5 of the 34 grandsire families analyzed. This QTL was detected in the same region as the complex vertebral malformation (CVM) gene found by Thomsen et al. (2006). Fine mapping in this region would be interesting to assess whether the same or, rather, closely linked genes cause the observed effects. The QTL for D-CS on BTA19 and BTA20 were also detected with high significance.

With the strong general correlations among the direct calving traits, finding a high proportion of pleiotropic QTL affecting them was expected. On BTA7, BTA18, and BTA25, QTL regions were found to affect more than 1 trait; and BTA18 had the clearest result and affected all direct calving traits and segregated in 5 grandsire families. The QTL on BTA7 is the only QTL region of the 4 QTL regions detected in this study in which a linked model was clearly favored. For the maternal traits, only 1 region was found to affect 2 traits (BTA28), but the analyses for this chromosome were not conclusive in terms of distinguishing between linkage and pleiotropy.

Five chromosome regions affect both direct and maternal traits (BTA8, BTA12, BTA18, BTA22, and 
Table 2. Chromosome-wise regression analysis across families for calving traits at first calving ${ }^{1}$

\begin{tabular}{|c|c|c|c|c|c|c|}
\hline Chromosome $^{2}$ & $\begin{array}{c}\text { Average } \\
\text { heterosity } \\
\text { of markers }\end{array}$ & $\begin{array}{l}\text { Grandsires } \\
\text { analyzed, } \mathrm{n}\end{array}$ & Trait $^{4}$ & Marker bracket/marker & $\begin{array}{c}P \text {-value } \\
(q \text {-value })^{5}\end{array}$ & $\begin{array}{l}\text { Segregating } \\
\text { grandsires, } \mathrm{n}\end{array}$ \\
\hline BTA3 & 8.5 & 34 & D-SB & BM7225 - BM2924 & $\begin{array}{c}0.010 \\
(0.063)\end{array}$ & 5 \\
\hline BTA4 & 5.0 & 19 & D-CD & TGLA116 - INRA072 & $\begin{array}{c}0.023 \\
(0.093)\end{array}$ & 3 \\
\hline \multirow[t]{2}{*}{ BTA7 } & 6.4 & 34 & D-SB & BMS2258 - OARAE129 & $\begin{array}{c}0.003 \\
(0.047)\end{array}$ & 6 \\
\hline & & & D-CS & OARAE129 - ILSTS006 & $\begin{array}{c}0.042 \\
(0.105)\end{array}$ & 5 \\
\hline \multirow[t]{2}{*}{ BTA8 } & 3.6 & 34 & D-CD & MCM64 - CSSM047 & $\begin{array}{c}0.042 \\
(0.105)\end{array}$ & 2 \\
\hline & & & M-SB & MCM64 - CSSM047 & $\begin{array}{c}0.030 \\
(0.093)\end{array}$ & 3 \\
\hline BTA9 & 6.0 & 19 & M-CS & BM2504 - BMS1267 & $\begin{array}{c}0.027 \\
(0.093)\end{array}$ & 3 \\
\hline BTA10 & 6.1 & 34 & M-CD & INRA037 - BMS1620 & $\begin{array}{c}0.035 \\
(0.100)\end{array}$ & 3 \\
\hline \multirow[t]{2}{*}{ BTA12 } & 5.1 & 19 & D-SB & AGLA232 & $\begin{array}{c}0.031 \\
(0.093)\end{array}$ & 1 \\
\hline & & & M-SB & AGLA232 & $\begin{array}{c}0.028 \\
(0.093)\end{array}$ & 2 \\
\hline BTA15 & 6.5 & 34 & D-CS & BMS927 - BMS429 & $\begin{array}{c}0.020 \\
(0.093)\end{array}$ & 3 \\
\hline \multirow[t]{4}{*}{ BTA18 } & 7.0 & 34 & D-CD & BM6507 - TGLA227 & $\begin{array}{c}0.010 \\
(0.063)\end{array}$ & 5 \\
\hline & & & D-SB & BM6507 - TGLA227 & $\begin{array}{c}0.026 \\
(0.093)\end{array}$ & 4 \\
\hline & & & D-CS & BM6507 - TGLA227 & $\begin{array}{c}0.000 \\
(0.000)\end{array}$ & 4 \\
\hline & & & M-SB & BMON117 -BMS2785 & $\begin{array}{c}0.015 \\
(0.086)\end{array}$ & 7 \\
\hline BTA19 & 5.2 & 19 & D-CS & BMS745 - BP20 & $\begin{array}{c}0.007 \\
(0.063)\end{array}$ & 3 \\
\hline BTA20 & 3.5 & 19 & D-CS & BM5004 - UWCA26 & $\begin{array}{c}0.005 \\
(0.063)\end{array}$ & 5 \\
\hline BTA21 & 5.3 & 34 & M-CD & ILSTS054 - BMS743 & $\begin{array}{c}0.044 \\
(0.044)\end{array}$ & 2 \\
\hline \multirow[t]{2}{*}{ BTA22 } & 4.1 & 19 & D-CS & BMS875 - BM4102 & $\begin{array}{c}0.010 \\
(0.063)\end{array}$ & 2 \\
\hline & & & M-CS & BM3628 - BMS875 & $\begin{array}{c}0.029 \\
(0.093)\end{array}$ & 3 \\
\hline BTA24 & 4.6 & 19 & M-SB & BMS1862 - BMS466 & $\begin{array}{c}0.041 \\
(0.104)\end{array}$ & 2 \\
\hline \multirow[t]{2}{*}{ BTA25 } & 3.0 & 19 & D-CD & BMS1353 - AF5 & $\begin{array}{c}0.006 \\
(0.063)\end{array}$ & 2 \\
\hline & & & D-CS & BMS1353 - AF5 & $\begin{array}{c}0.002 \\
(0.042)\end{array}$ & 4 \\
\hline \multirow[t]{2}{*}{ BTA26 } & 4.7 & 34 & D-SB & BMS882 - BM804 & $\begin{array}{c}0.021 \\
(0.093)\end{array}$ & 3 \\
\hline & & & M-SB & BM804 - BM7237 & $\begin{array}{l}0.000 \\
(0.000)\end{array}$ & 7 \\
\hline \multirow[t]{2}{*}{ BTA28 } & 3.5 & 33 & M-CD & ETH1112 - BL25 & $\begin{array}{c}0.025 \\
(0.093)\end{array}$ & 3 \\
\hline & & & M-SB & BL25 - BMS2608 & $\begin{array}{c}0.045 \\
(0.105)\end{array}$ & 0 \\
\hline
\end{tabular}

${ }^{1}$ The QTL are shown for traits that exceed the 5\% chromosome-wise threshold level of significance. ${ }^{2} \mathrm{BTA}=$ Bos taurus autosome.

${ }^{3}$ Average heterozygosity of markers are used as criteria for information level of each chromosome.

${ }^{4}$ Analyzed traits: D-CD = direct calving difficulty; D-SB = direct stillbirth; $\mathrm{D}-\mathrm{CS}=$ direct calf size; $\mathrm{M}-\mathrm{CD}=$ maternal calving difficulty; M-SB = maternal stillbirth; M-CS = maternal calf size.

${ }^{5} q$-value is the genome-wise false discovery rate. 
Table 3. Multitrait analysis with pleiotropic and linked QTL models for calving traits on Bos taurus autosome (BTA) $7,8,12,18,22,25,26$, and 28

\begin{tabular}{llcccc}
\hline Chromosome & Traits $^{1}$ & $\mathrm{r}_{\mathrm{q}}{ }^{2}$ & $\begin{array}{c}\text { Distance } \\
(\mathrm{cM})\end{array}$ & Markers, $^{3} \mathrm{n}$ & $\begin{array}{c}\text { Bayes } \\
\text { factor }^{4}\end{array}$ \\
\hline BTA7 & D-SB, D-CS & 0.35 & 26 & 1.15 & 0.3 \\
BTA8 & D-CD, M-SB & $\mathrm{NC}^{5}$ & 38 & 1.12 & NC \\
BTA12 & D-SB, M-SB & 0.99 & 4 & 0 & 27 \\
BTA18 & D-CD, D-SB & 0.87 & 0 & 0 & 27 \\
& D-CD, D-CS & 0.93 & 0 & 0 & 109,848 \\
& D-CD, M-SB & 0.71 & 14 & 1.15 & 0.7 \\
& D-SB, D-CS & 0.95 & 0 & 0 & NC \\
BTA22 & D-SB, M-SB & NC & 14 & 1.15 & 0.7 \\
BTA25 & D-CS, M-SB & 0.49 & 14 & 1.15 & 3.7 \\
BTA26 & D-CS, M-SB & 0.72 & 14 & 0.68 & 548 \\
BTA28 & D-CD, D-CS & 1.00 & 0 & 0 & 0.13 \\
\hline
\end{tabular}

\footnotetext{
${ }^{1}$ Traits: $\mathrm{D}-\mathrm{CD}=$ direct calving difficulty; D-SB = direct stillbirth; D-CS = direct calf size; $\mathrm{M}-\mathrm{CD}$ = maternal calving difficulty; M-SB = maternal stillbirth; M-CS = maternal calf size.

${ }^{2} \mathrm{r}_{\mathrm{q}}=$ correlation between QTL effects of the 2 traits.

${ }^{3}$ Number of markers is the average number of informative markers between QTL.

${ }^{4}$ The Bayes factor is an approximate Bayes Factor for the comparison of the pleiotropic model to the linked model.

${ }^{5} \mathrm{NC}=$ not conclusive.
}

BTA26). Genetic correlations of direct calving traits and maternal calving traits are generally weak. Parameters used in Danish Holstein breeding value estimation vary from 0.02 to 0.07 (Aamand, 2002). Thus, it would be expected that only very few chromosome regions affect both the direct and maternal calving traits. The pleiotropic model was favored for BTA12, and this was the only region affecting both direct and maternal SB. In contrast, the linkage model was favored on BTA26.

In general, there was a balance favoring both linked and pleiotropic models both for comparisons of directdirect calving traits and for comparisons of direct-maternal calving traits (Table 3). Probabilities for the pleiotropic model in general were higher compared with the situations in which the linked model was favored. The number of markers between the QTL positions estimated from the single-trait analysis in these regions was probably too low to give strong evidence to separate the effect and favor the linkage model. The actual numbers of informative markers varied from 0 to 1.2 in regions with distances between QTL positions from 4 to $38 \mathrm{cM}$, which might be too low.

In total, 3 of the detected QTL supported the findings of other studies. The QTL for D-CD on BTA8 confirmed the result from Ashwell et al. (2005) and the QTL for D-SB and M-SB on BTA7 and BTA18 confirmed the results in Kühn et al. (2003). The QTL for calving traits found by Holmberg and Andersson-Eklund (2006) were not supported in this study.

The QTL identified could have important implications for the Danish Holstein breeding program, because calving traits are given a relatively heavy eco- nomic weight in the Danish combined selection index. In particular, QTL affecting CD and SB without affecting CS will be an efficient way for genetic improvement of calving traits. Some of the identified QTL might be false positives, as discussed earlier. Therefore, it is important to focus selection on QTL regions with a dense marker map and high numbers of segregating families per trait to minimize the risk of putting selection pressure on false-positive QTL. In some regions, the confidence intervals for QTL effects are quite large; thus, the only information that can differentiate between close linkage and pleiotropy are the correlations between QTL effects on the 2 traits. More markers in these regions are needed to draw more precise conclusions about the behavior of the QTL in the region.

Selection for the positive QTL allele on BTA3 can reduce $\mathrm{SB}$ as a direct trait, whereas selection for the positive QTL allele on BTA4 will reduce CD. Selection for the favorable QTL allele on BTA7 to decrease the number of stillborn calves will, in general, also decrease CS. Therefore, breeding organizations are recommended to select bulls in which the 2 QTL alleles have recombined. Selecting these bulls would improve SB for their calves without decreasing the CS. With an estimated distance between the 2 QTL positions of 26 $\mathrm{cM}$, it is possible to select for the recombinant bulls. Four chromosomes seem only to affect maternal traits, whereas BTA10 and BTA21 can both reduce M-CD; BTA24 can reduce M-SB; and BTA28 can decrease MCD and M-SB. The QTL on BTA18 should be used to select for improved M-SB; and BTA12 and BTA26 affect both direct and maternal SB. This indicates that a re- 
cessive lethal allele causing SB may be present in these regions. A more detailed study involving the segregating families is needed to confirm this hypothesis.

\section{ACKNOWLEDGMENTS}

We thank the Danish Cattle Federation (Aarhus, Denmark) for providing phenotypic data. This project was funded by FREM98 DJF: New technologies in farm animals breeding and j.no. 34016503 136: DNA based selection to improve disease resistance, fertility, calf survival and production in Danish dairy cattle from the Danish Directorate for Food, Fisheries and Agri Business. The authors thank the anonymous reviewers for useful comments.

\section{REFERENCES}

Aamand, G. P. 2002. Avlsværdivurdering. Forbedringer indført i 2000-2001. Rep. No. 99, National Committee on Danish Cattle Husbandry. U. S. Nielsen, J. Pedersen, A. Fogh, O. M. Pedersen, M. Hansen, A. Glasius, P. Madsen, and J. Jensen, ed. National Committee on Danish Cattle Husbandry, Aarhus, Denmark.

Ashwell, M. S., D. W. Heyen, J. I. Weller, M. Ron, T. S. Sonstegard, C. P. Van Tassell, and H. A. Lewin. 2005. Detection of quantitative trait loci influencing conformation traits and calving ease in Holstein-Friesian cattle. J. Dairy Sci. 88:4111-4119.

Buitenhuis, A. J., M. S. Lund, J. R. Thomasen, B. Thomsen, V. H. Nielsen, C. Bendixen, and B. Guldbrandtsen. 2007. Detection of quantitative trait loci affecting lameness and leg conformation traits in Danish Holstein cattle. J. Dairy Sci. 90:472-481.

Churchill, G. A., and R. W. Doerge. 1994. Empirical threshold values for quantitative trait mapping. Genetics 138:963-971.

Dempster, A. P., N. M. Laird, and D. B. Rubin. 1977. Maximum likelihood from incomplete data via the EM algorithm. J. R. Stat. Soc. Ser. B Met. 39:1-38.

Elo, K. T., J. Vilkki, D. J. de Koning, R. J. Velmala, and A. V. MäkiTanila. 1999. A quantitative trait locus for live weight maps to bovine chromosome 23. Mamm. Genome 10:831-835.

Haldane, J. B. S. 1919. The combination of linkage values and the calculation of distances between the loci of linked factors. J. Genet. 8:299-309.

Hansen, M. 2004. Quantitative genetic analysis of mortality in Danish Holstein calves. PhD Thesis. The Royal Veterinary and Agricultural University, Copenhagen, Denmark.

Hansen, M., M. S. Lund, J. Pedersen, and L. G. Christensen. 2004. Genetic parameters for stillbirth in Danish Holstein cows using a Bayesian threshold model. J. Dairy Sci. 87:706-716.
Holmberg, M., and L. Andersson-Eklund. 2006. Quantitative trait loci affecting fertility and calving traits in Swedish dairy cattle. J. Dairy Sci. 89:3664-3671.

Johnson, D. L., and R. Thompson. 1994. Restricted maximum likelihood estimation of variance components for univariate animal models using sparse matrix techniques and average information. J. Dairy Sci. 78:449-456.

Kass, E. R., and A. E. Raftery. 1995. Bayes factors. J. Am. Stat. Assoc. 90:773-795.

Kühn, Ch., J. Bennewitz, N. Reinsch, N. Xu, H. Thomsen, C. Looft, G. A. Brockmann, M. Schwerin, C. Weimann, S. Hiendleder, G. Erhardt, I. Medjugorac, M. Forster, B. Brenig, F. Reinhardt, R. Reents, I. Russ, G. Averdunk, J. Blumel, and E. Kalm. 2003. Quantitative trait loci mapping of functional traits in the German Holstein cattle population. J. Dairy Sci. 86:360-368.

Lund, M. S., P. Sørensen, B. Guldbrandtsen, and D. A. Sorensen. 2003. Multitrait fine mapping of quantitative trait loci using combined linkage disequilibria and linkage analysis. Genetics 163:405-410.

Madsen, P., J. Jensen, and R. Thompson. 1994. Estimation of (co)variance components by REML in multivariate mixed linear models using average of observed and expected information. Pages 455462 in Proc. 5th WCGALP, Guelph, Canada.

Danish Cattle Federation. 2006. Principles of Danish Cattle Breeding. 8th ed. Online. http://www.lr.dk/kvaeg/diverse/principles.pdf Accessed Jan. 18, 2006.

Madsen, P., P. Sørensen, G. Su, L. H. Damgaard, H. Thomsen, and R. Labouriau. 2006. DMU - A package for analyzing multivariate mixed models. Page 247 in Book of Abstracts: CD communication 27-11. 8th WCGALP, Belo Horizonte, Brazil.

Pedersen, J. 2003. S-indeks for tyre af malke-og kombinationsracer 2002. U. S. Nielsen and G. P. Aamand, ed. National Committee on Danish Cattle Husbandry, Aarhus, Denmark.

Schrooten, C., H. Bovenhuis, W. Coppieters, and J. A. M. Van Arendonk. 2000. Whole genome scan to detect quantitative trait loci for conformation and functional traits in dairy cattle. J. Dairy Sci. 83:795-806.

Schwarz, G. 1978. Estimating the dimension of a model. Ann. Statist. 6:461-464.

Sørensen, P., M. S. Lund, B. Guldbrandtsen, J. Jensen, and D. A. Sorensen. 2003. A comparison of bivariate and univariate QTL mapping in livestock populations. Genet. Sel. Evol. 35:605-622.

Storey, J. D., and R. Tibshirani. 2003. Statistical significance for genomewide studies. Proc. Natl. Acad. Sci. USA 100:9440-9445.

Thomsen, B., P. Horn, F. Panitz, E. Bendixen, A. H. Petersen, L. E. Holm, V. H. Nielsen, J. S. Agerholm, J. Arnbjerg, and C. Bendixen. 2006. A missense mutation in the bovine SLC35A3 gene, encoding a UDP-N-acetylglucosamine transporter, causes complex vertebral malformation. Genome Res. 16:97-105.

Weller, J. I., Y. Kashi, and M. Soller. 1990. Power of daughter and granddaughter designs for determining linkage between marker loci and quantitative trait loci in dairy cattle. J. Dairy Sci. 73:2525-2537. 